\title{
Erratum to: Shell thickness and pore density in relation to shell colouration, female characteristics, and environmental factors in the Collared Flycatcher Ficedula albicollis
}

\author{
Rita Hargitai · Rafael Mateo · János Török
}

Published online: 12 February 2011

(c) Dt. Ornithologen-Gesellschaft e.V. 2011

Erratum to: J Ornithol

DOI 10.1007/s10336-010-0627-4

In the original publication of this article, the citation of Herényi et al. (2010) is incorrect. The correct citation is Herényi et al., unpublished data.

The online version of the original article can be found under doi:10.1007/s10336-010-0627-4.

R. Hargitai $(\bowtie) \cdot$ J. Török

Behavioural Ecology Group, Department of Systematic Zoology and Ecology, Eötvös Loránd University, Pázmány P. sétány 1/C, 1117 Budapest, Hungary

e-mail: harrita@freemail.hu

Present Address:

R. Hargitai

Institute of Environmental Sciences, College of Nyíregyháza,

Sóstói út 31/B, 4401 Nyíregyháza, Hungary

R. Mateo

Instituto de Investigación en Recursos Cinegéticos,

CSIC-UCLM, Ronda de Toledo $\mathrm{s} / \mathrm{n}$,

13005 Ciudad Real, Spain 